\title{
Gastro-oesophageal Reflux, Some Data on Diagnosis and Clinical Evaluation
}

\author{
Saimir Heta*, Kastriot Haxhirexha, Virtut Velmishi, Nevila Alliu, Ilma Robo \\ Department of Pediatric Surgery, QSUT, Tirana, Albania
}

*Corresponding Author: Saimir Heta, Department of Pediatric Surgery, QSUT, Tirana, Albania

Email: sa.heta@yahoo.com

\begin{abstract}
Introduction: Treatment of gastro-oesophageal reflux involves number of therapeutic measures that eventually conclude with surgical treatment. It should be noted that surgical treatment should be the last resort to be used to treat this pathology, due to the complications and recurrences that this surgery may give.
\end{abstract}

Materials and Methods: This study included 59 children operated for gastro-oesophageal reflux with the laparoscopic method and for the same period 14 children operated with the open method. By gender in these two groups the study involves 34 males and 25 females in the first group of laparoscopic methods and 8 males and 6 females in the open method group. The average age of the treated children was 13.21 and 12.56 years old in the laparoscopic method, 7.34-year-old males and 8.15-year-olds in the open method.

Children after being diagnosed by radiology, pharmacology and after having received a proton pump prolonged long-term treatment for indications, were planned for intervention. Prior to the intervention, the child is evaluated in all respects and is subject to the full anesthetic protocol. Including biochemical balance, complete blood, cholesterol, blood group. The child is treated with general anesthesia with endotracheal intubation using as anesthetic inhaler and intravenous subjects.

Conclusions: Gastro-oesophageal reflux at childhood is a disease that has long been given particular attention, by both, pediatricians and pediatric surgeons. A pathology that in its benign form, that is nonpathological reflux captures, a very large percentage of children in the first year of life where, according to some studies, appears in 50\% of cases with a maximum prevalence rise in the 4th month of life, in our results this aspect is not vulnerable, because we have only studied children who have been subjected to intervention. So are those children who have gone through all the main links of diagnosis and conservative treatment.

Keywords: gastro-oesophageal reflux, open method, laparoscopy

\section{INTRODUCTION}

Treatment of gastro-oesophageal reflux involves number of therapeutic measures that eventually conclude with surgical treatment. It should be noted that surgical treatment should be the last resort to be used to treat this pathology, due to the complications and recurrences that this surgery may give. The age of the patient's presentation the presence of complications or predisposing factors is a clue that helps us in treating this pathology. The vomiting without strain that occurs to the latitudes after the meal, is a symptom that can't be called a disease that calms if the latent after food is kept in elevated position. With the maturation of the lower esophagus sphincter this calms down and disappears almost over time. Seeing that the symptom was lifted from the raised position, it was thought to be used chalasia chair (chalasia chair). It was soon noticed that this resulted in the increase in reflux (1), compared to the placement of children in the 30th grade. But it has been seen that the use of this overturning position is not without consequences and should be carefully applied according to a study (2) that the use of this position should be recognized as a treatment that has side effects associated with drug therapy. In a study (3) that sees the SIDS connection with the position, it is not recommended to use lateral positioners and that the child should be placed in the back position. This is the recap of AAP American Academy of Pediatric. Another method of treating these children is the obesity of the products they receive. This is not very applicable to the infact. As a thickener can use rice cereal flour. Now the pharmaceutical industry is approaching number 
of solutions. The use of medications in the treatment of gastro-oesophageal reflux is a tangible reality. Use of motilium or cisapride which is a prokinetic agent that has very good clinical effects. The preparation has been shown to increase peristalsis increases the pressure of the lower esophagus sphincter and accelerates the gastric rupture. (4) In adults, the preparation is associated with causing cardiac arrhythmias that have been fatal. But the discovery of cardiac problems that this product could give in America led to the withdrawal from the market (5). However, it is in use with us, but it should be taken in account that treatment with it, should be as limited and prudent due to these complications.

\section{MATERIALS AND METHODS}

This study included 59 children operated for gastro-oesophageal reflux with the laparoscopic method and for the same period 14 children operated with the open method. By gender in these two groups the study involves 34 males and 25 females in the first group of laparoscopic methods and 8 males and 6 females in the open method group. The average age of the treated children was 13.21 and 12.56 years old in the laparoscopic method, 7.34-year-old males and 8.15 -year-olds in the open method.

Children after being diagnosed by radiology, pharmacology and after having received a proton pump prolonged long-term treatment for indications, were planned for intervention. Prior to the intervention, the child is evaluated in all respects and is subject to the full anesthetic protocol. Including biochemical balance, complete blood, cholesterol, blood group. The child is treated with general anesthesia with endotracheal intubation using as anesthetic inhaler and intravenous subjects.

The data for these two groups were obtained through an elaborated type file with the help of statists from the BurloGarafolol Trieste Italy Institute. Data is collected prospectively based on this type file. The data has been collected and described in such a way that it is statistically analyzable. Type card data included: age, sex, anti-acid therapy, pathological morphology, fibrogastroscopy data, biopsy, impendecometry, barium passage.

During the study was evaluated the degree of scoliosis, the neurological clinic, the cause of neurological pathology, preoperative nutrition, the baseline pathology was examined according to ASA classification. During the study, respiratory insurances, the use of barbiturates, the type of anesthesia used, postoperative analgesia, the use of sedatives, the time of extubation, reinturbation, and respiratory assistance were evaluated. The intervention was considered, the laparoscopic approach to the open method.

\section{Results}

Demographic data

Table1. Gender - Laparoscopic Group

\begin{tabular}{|l|l|l|l|}
\hline & Frequency & Percentage & $\begin{array}{l}\text { Cumulative } \\
\text { Percentage }\end{array}$ \\
\hline Male & 34 & 57.63 & 57.63 \\
\hline Female & 25 & 42.37 & 100.00 \\
\hline Total & 59 & 100.00 & \\
\hline
\end{tabular}

This table shows male demographic data for the first group.

Table2. Gender Group Open Method

\begin{tabular}{|l|l|l|l|}
\hline & Frequency & Percentage & $\begin{array}{l}\text { Cumulative } \\
\text { Percentage }\end{array}$ \\
\hline Male & 8 & 57.14 & 57.14 \\
\hline Female & 6 & 42.86 & 100.00 \\
\hline Total & 14 & 100.00 & \\
\hline
\end{tabular}

It is seen that the percentage and the second group is almost identical to the first group.

Table3. Average age

\begin{tabular}{|l|l|l|l|}
\hline & $\begin{array}{l}\text { Average } \\
\text { laparoscopic } \\
\text { age }\end{array}$ & $\begin{array}{l}\text { Average } \\
\text { age open } \\
\text { method }\end{array}$ & P \\
\hline Male & $13.21 \pm 2.2$ & $7.34 \pm 3.4$ & 0.00568 \\
\cline { 1 - 2 } Female & $12.56 \pm 2.7$ & $8.15 \pm 2.4$ & \\
\cline { 1 - 3 } $\begin{array}{l}\text { Total } \\
\text { average }\end{array}$ & $12.7 \pm 2.5$ & $7.8 \pm 3.1$ & \\
\hline
\end{tabular}

This table shows an important statistical difference between the average age of both groups.

Preoperative data

Table4. Refractive Therapy Group of Laparoscopic Methodes

\begin{tabular}{|l|l|l|l|}
\hline $\begin{array}{l}\text { Therapy } \\
\text { antacid }\end{array}$ & Frequency & Percentage & $\begin{array}{l}\text { Cumulative } \\
\text { Percentage }\end{array}$ \\
\hline Antiacid & 2 & 3.39 & 3.39 \\
\hline Omeprazol & 49 & 83.05 & 86.44 \\
\hline $\begin{array}{l}\text { Omeprazol } \\
\text { and antiacid }\end{array}$ & 8 & 13.56 & 100.00 \\
\hline Total & 59 & 100.00 & \\
\hline
\end{tabular}

This table shows the use of preoperative therapy in all first group patients, divided by type of medication. 
Table5. Antireflective Therapy Open Method Group

\begin{tabular}{|l|l|l|l|}
\hline $\begin{array}{l}\text { Therapy } \\
\text { antacid }\end{array}$ & Frequency & Percentage & $\begin{array}{l}\text { Cumulative } \\
\text { Percentage }\end{array}$ \\
\hline Omeprazol & 9 & 64.28 & 64.28 \\
\hline $\begin{array}{l}\text { Omeprazol } \\
\text { and antiacid }\end{array}$ & 5 & 35.72 & 100.00 \\
\hline Total & 14 & 100.00 & \\
\hline
\end{tabular}

This table shows the use of preoperative therapy in all second group patients, divided by type of medication.

As noted, anti-acid therapy is used in all patients involved in both groups.

Table6. Pathological morphology Laparoscopic Method Group

\begin{tabular}{|l|l|l|l|}
\hline $\begin{array}{l}\text { Pathologic } \\
\text { morphology }\end{array}$ & Frequency & Percentage & $\begin{array}{l}\text { Cumulative } \\
\text { Percentage }\end{array}$ \\
\hline $\begin{array}{l}\text { Cardiac } \\
\text { intrathoracic }\end{array}$ & 6 & 10.17 & 10.17 \\
\hline $\begin{array}{l}\text { Hernia } \\
\text { paraesophageal }\end{array}$ & 7 & 11.86 & 22.03 \\
\hline Hernia hiatale & 18 & 30.51 & 52.54 \\
\hline $\begin{array}{l}\text { Reflux without } \\
\text { noticeable } \\
\text { cause }\end{array}$ & 28 & 47.46 & 100.00 \\
\hline Total & 59 & 100.00 & \\
\hline
\end{tabular}

In this table it is evidenced radiological findings in the laparoscopic methotrexate group by which we determined the anatomical cause of pathology. As noted in the data in $47 \%$ of cases it has not been possible to detect an actual anatomical cause of reflux.

Table7. Pathological Morphology Open Method Group

\begin{tabular}{|l|l|l|l|}
\hline $\begin{array}{l}\text { Pathologic } \\
\text { morphology }\end{array}$ & Frequency & Percentage & $\begin{array}{l}\text { Cumulative } \\
\text { Percentage }\end{array}$ \\
\hline $\begin{array}{l}\text { Cardiac } \\
\text { intrathoracic }\end{array}$ & 3 & 21.43 & 21.43 \\
\hline $\begin{array}{l}\text { Hernia } \\
\text { paraesophageal }\end{array}$ & 1 & 7.14 & 28.57 \\
\hline Hernia hiatale & 4 & 28.57 & 57.14 \\
\hline $\begin{array}{l}\text { Reflux without } \\
\text { noticeable } \\
\text { cause }\end{array}$ & 6 & 42.86 & 100.00 \\
\hline Total & 14 & 100.00 & \\
\hline
\end{tabular}

In this table we have evidenced radiological findings in the open methotrexate group, where in the case of the first group we have determined the anatomical cause of the pathology. It is noticed an approximate frequency of the anatomical cause of pathology as in the case of the first group.

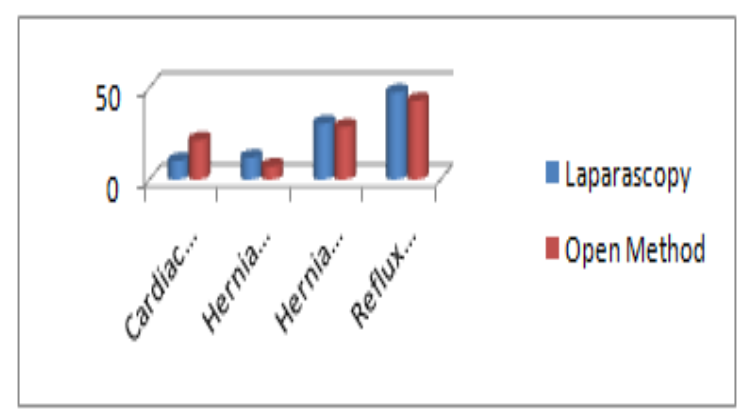

Graph1. Pathological morphology

Table8. Preoperative Fibrogastrosopopy Laparoscopic Method Group

\begin{tabular}{|l|l|l|}
\hline Fibrogastroscopy & Frequency & Percentage \\
\hline It's not done & 15 & 25.42 \\
\hline Reflux sign & 17 & 28.81 \\
\hline $\begin{array}{l}\text { The presence of } \\
\text { hiataryhernies }\end{array}$ & 13 & 22.03 \\
\hline $\begin{array}{l}\text { Herniehiatale + } \\
\text { esophagitis }\end{array}$ & 14 & 23.73 \\
\hline Total & 59 & 100.00 \\
\hline
\end{tabular}

The table presents fibroscopic data in laparoscopic patients. As seen in fibroscopy is a widely used examination, in almost $74 \%$ of patients. By this method we had the opportunity to determine the esophagitis morphologically and at the same time to obtain the histological material.

Table9. Preoperative Fibrogastrosopopy Open Method Group

\begin{tabular}{|l|l|l|}
\hline Fibrogastroscopy & Frequensy & Percentage \\
\hline It's not done & 7 & 50.00 \\
\hline Reflux sign & 2 & 14.29 \\
\hline $\begin{array}{l}\text { The presence of } \\
\text { hiataryhernies }\end{array}$ & 2 & 14.29 \\
\hline $\begin{array}{l}\text { Herniehiatale } \\
\text { esophagitis }\end{array}$ & 3 & 21.42 \\
\hline Total & 14 & 100.00 \\
\hline
\end{tabular}

The table represents fibroscopic data in open method group patients. As it is noticed, fibroscroscopy is not performed in $50 \%$ of cases and this is more for objective reasons. In cases that have been performed in all cases, we have found signs of gastro-oesophageal pathology.

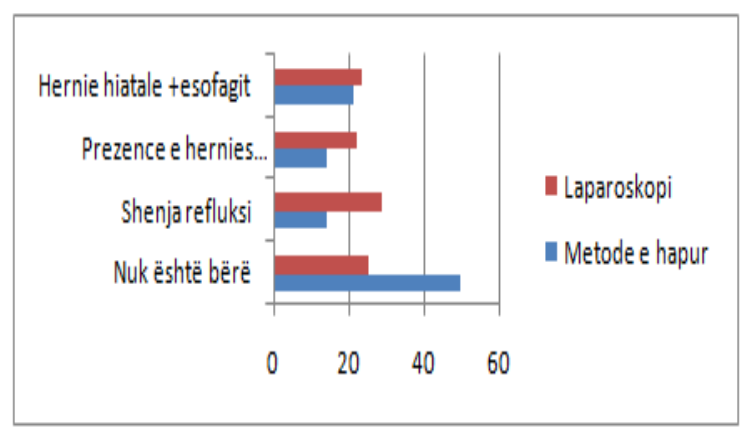

Graph2. Preoperative Fibrogastrosopics 
Table10. Histology

\begin{tabular}{|l|l|l|}
\hline Histology & Frequensy & Percentage \\
\hline It's not done & 36 & 61.02 \\
\hline Esofagit & 22 & 37.29 \\
\hline Ezofag Barret & 1 & 1.69 \\
\hline Total & 59 & 100.00 \\
\hline
\end{tabular}

The table presents the histological data in the patients of the first group. In all cases in which biopsy was performed, the presence of esophagitis was noted. Histology is one of the finest points of an accurate diagnosis.

Table11. Impednometry

\begin{tabular}{|l|l|l|}
\hline Impednometry & Frequensy & Percentage \\
\hline Normal reflux & 3 & 5.08 \\
\hline Pathological Reflux & 14 & 23.73 \\
\hline $\begin{array}{l}\text { It has not been } \\
\text { completed }\end{array}$ & 42 & 71.19 \\
\hline Total & 59 & 100.00 \\
\hline
\end{tabular}

Impendencecometer a coherent examination presents a sensitivity of about $82 \%$ in this series.

Table12. Binding Clinical Data - Impednometer

\begin{tabular}{|l|l|l|}
\hline Klinik -impendcometri & Frequensy & Percentage \\
\hline Clinical compatibility & 7 & 11.86 \\
\hline No clinical compatibility & 3 & 5.08 \\
\hline Not done & 49 & 83.05 \\
\hline Total & 59 & 100.00 \\
\hline
\end{tabular}

In the table there is a consistency between clinical data and impendometry that goes to $70 \%$ of cases. The data show a lower sensitivity of impendecometry, but this connection was realized in only 10 patients concluding that sensitivity is approximate.

Table13. Degree of Scoliosis

\begin{tabular}{|l|l|l|}
\hline Scoliosis & Frequensy & Percentage \\
\hline $\mathbf{0}$ & 9 & 15.25 \\
\hline $\mathbf{1}$ & 22 & 37.29 \\
\hline $\mathbf{2}$ & 22 & 37.29 \\
\hline $\mathbf{3}$ & 5 & 8.47 \\
\hline $\mathbf{4}$ & 1 & 1.69 \\
\hline Total & 59 & 100.00 \\
\hline
\end{tabular}

O- no scoliosis

$1-<10$ grade without any symptoms

2-> 25 grade with light pulmonary symptom

3-> 40 grades with indications for intervention

4-> 70 grade with pulmonary volume reduction

Scoliosis as one of the predisposing factors in gastro-oesophageal reflux is analyzed in this chart. $10 \%$ of patients have a 3-4 level scoliosis that can cause anesthetic complications and operators.

Table14. Neurological clinic

\begin{tabular}{|l|l|l|}
\hline Neurological clinic & Frequensy & Percentage \\
\hline $\begin{array}{l}\text { Without neurological } \\
\text { problems }\end{array}$ & 16 & 27.12 \\
\hline Only dementia & 1 & 1.69 \\
\hline Neuropathy flashed & 3 & 5.08 \\
\hline Tetraparesis spastic & 39 & 66.10 \\
\hline Total & 59 & 100.00 \\
\hline
\end{tabular}

Above is the neurological data of patients, where there is a high frequency of the presence of neurological pathologies.

It is clear, only $27 \%$ of patients have no neurological problems.

Table15. The cause of neurological pathology

\begin{tabular}{|l|l|l|}
\hline $\begin{array}{l}\text { The cause of } \\
\text { neurological pathology }\end{array}$ & Frequensy & Percentage \\
\hline Without pathology & 12 & 20.34 \\
\hline Prematurity & 2 & 3.39 \\
\hline Perinatal Asphyxiation & 26 & 44.07 \\
\hline Malformation SNQ & 10 & 16.95 \\
\hline $\begin{array}{l}\text { Chromosome } \\
\text { abnormalities }\end{array}$ & 6 & 10.17 \\
\hline Brain Infection & 2 & 3.39 \\
\hline Fealopathic syndrome & 1 & 1.69 \\
\hline Total & 59 & 100.00 \\
\hline
\end{tabular}

\section{DISCUSSIONS}

Gastro-oesophageal reflux at childhood is a disease that has long been given particular attention by both pediatricians and pediatric surgeons. A pathology that in its benign form that is non-pathological reflux captures a very large percentage of children in the first year of life (6) where, according to some studies, appears in $50 \%$ of cases with a maximum prevalence rise in the 4th month of life. In our results this aspect is not vulnerable because we have only studied children who have been subjected to intervention. So are those children who have gone through all the main links of diagnosis and conservative treatment. It is nearly identical number of males and females in the laparoscopic group (Table 1) and in the open method group (Table 2). It is seen that we have a percentage of about $57 \%$ of men. This ratio of male women is also found in literature (7-9). When we look at the average age of childishly treated children, we notice a large change in the average age of the two groups (Table 3). This has come for several reasons. The first reason is that in the laparoscopic group are treated children up to 18 years of age, whereas in our 
group we have treated children with a maximum age of 14 due to the different rules applied by the pediatric surgery clinic in Albania and Italy. But the other factor is that in the laparoscopic group there are many children who are neurological or scoliosis children so they have a diagnosed gastro-oesophageal reflux disease at a later stage. When we look at the results we can see that conservative treatment (Table 4) is used in all patients. Use of other proton pump inhibitors where omeprazole is the typical proponent. is an innovation that embraced more enthusiasm. The first reports have been very encouraging $(10,11)$ by seeing the Proton Pump Frenus (PPI) as a solution to the problem that could and was an alternative to intervention. Even in some books, it was seen as new era in the treatment of pathological reflux. But over time, this enthusiasm has fallen, seeing that recent studies (12) the effect of PPI on infants is low although no comparative studies with placebo have been conducted. Thus, the general impression is that the use of omeprazole is safe (13) as a therapeutic treatment but its efficacy is not proven. Using omeprazole is a drug that is highly effective for treating esophagitis. Thus, the use of omeprazole has a good effect on the treatment of symptoms of gastro-oesophageal reflux for this reason its use is one of the most effective conservative therapies in treating gastroesophageal reflux (13, 34). However, there are studies (12) that accuse him of a rise in gastroenteritis and an increase in pneumonia. As we have said above, it is also accused of hypomagnesis or of bone fractures. Omeprazole two study groups were used in all patients before intervention (Table 4.5). Diagnosis of gastro-oesophageal reflux besides clinical suspicion should pass into an examination protocol involving imaging study. This examination is a key examination in diagnosing gastro-oesophageal reflux as well as establishing a direct relationship between the clinic and pathology. What is important is that through this examination we can realize a prediction of anatomy or rather of the pathological morphology that caused this pathology before intervening. In our series, imaging is performed in all patients. (Table 6,7). Through it we find that in $52.54 \%$ of cases we have found an anatomical factor such as intrathoracic kardia, parahexa phage hernia, hiatary hernia. But in the rest of the patients, only pure esophageal reflux is observed. We say that we have not seen a tangible anatomical factor. And in the series operated there is the same pathology determining pathology. What is worth noting is that contrast imaging with the upper tract is a conventional image that has been protocols for many years. One of the important phases of the imaging protocol is the trendelenbourg position that is needed to determine especially cases with pure esophageal reflux where the anatomical changes are not imaging-susceptible. The accuracy of imaging diagnosis is an open debate where it is thought that using ph-metrix is the most reliable method. (16) In this study it is seen that the barium study is lower than the phmeter, $36 \%$ at $70 \%$. By comparing it with clinical data which in our opinion is not very accurate. (17) The fact of the accuracy of the imaging study can't be taken very basically by looking at our tables because we do not intervene in children unless we had a positive image. So, for us imaging is the key study in the diagnosis of gastro-oesophageal reflux and in determining surgical indications. So, determining the sensibility of this method is beyond the possibilities of this study. Differential diagnosis that can be accomplished through barium scopy is one of the strengths that this examination has. By means of it, it is possible to diagnose or suspect the possibility of mesenteritis, duodenal membrane, hypertrophic pylori stenosis. It seems that these pathologies are clearly separated from the clinic and the diagnosis of gastro-oesophageal reflux but the daily experience shows that this examination is often the case that has led us to an accurate diagnosis in diagnosing the errors of diagnosis. This is very important especially in the case of laparoscopic surgery because this surgery does not give us the possibility of intraoperative tactility that the diagnosis should be as accurate as possible. In (Graph 1) we have visually presented Table 6.7 data. It is seen that there is no significant difference in the percentage between imaging findings in both groups. Use of fibrogastroscopy as a sourcing and sometimes defining method. It is performed in more than $75 \%$ of cases. As can be seen in (Table 8) it is a routine method that has given us quite valuable data. Through it we have received information about reflux, esophagitis and presence of hiatary hernias. Fibrogastoscopy may well diagnose esophageal which is one of the inflammatory consequences of gastro-oesophageal reflux. But on the other hand, to determine the degree of esophagitis and to have a precise indication of the morphological changes and at the cellular 
level, biopsy may also be performed. With the histology sections can be determined the esophagitis its degree and can also be diagnosed with the precancerous metaplasia like Barret's esophagus (18-20). Fibrogastrocopy also diagnoses hiatal hernias especially when they are large, allowing us to have a very accurate diagnosis and defined a more detailed operator plan. As seen from (Tables 8, 9) and from (Graph 2) fibrogastroscopy was performed in the first group in more than $75 \%$ of cases and in the second group in only $50 \%$ of cases. In (Table 10) it is clearly seen that the use of histology so differently of biopsy is a datum that concedes us in a more and more accurate diagnosis. The esophagus biopsy is not a routine exercise. The biopsy was performed in $37.29 \%$ of the cases. But taking in account that fibroscopy is performed in $75 \%$ of cases it is seen that the biopsy was performed in $52.27 \%$ of the cases that have performed fibrogastricopy in more than half of the patients. This has resulted in a clear morphological diagnosis. In children treated with us the esophagus biopsy is not an action that is still being protocols and has not been performed. It should be taken in account that the diagnosis of esophagitis does not interfere with interventionism (21). On the other hand, fibrogatroscopy and more esophageal biopsy in young children is an action that requires special susceptibility and a special technical skill (22). It is an action that may have its own complications and so in the balance benefit the risk at the time of the study it is seen that the benefit was scarce. One of the most important examinations we have and a diagnosis with a very high accuracy is impendecometry. Impendencometry is an examination that not only measures acid reflux but mats and refluxes are not acidic themselves. As a compiled and contemporaneous examination, one of the basic studies is how to diagnose how to carry out comparative studies because being digitized data is a measurable and comparable study. It is widely used in the patients analyzed in the first group. In (Table 11) it is seen that the use of impendencometry has been performed in 17 cases where the sensitivity in the group that has performed this examination is $82 \%$. This is a lump which is lower than what is referred to in literature where the sensitivity of impendecometry is about $90 \%$. According to many authors (22-25) it is seen that the ph-meter is considered as (gold standard) for the diagnosis of this pathology.

\section{ACKNOWLEDGMENTS}

Our thanks belong to our family. Henri and Hera drive us forward, and further in the field of scientific research.

\section{AUTHOR CONTRIBUTIONS}

Literature research was conducted by Dr. SaimirHeta. It was his insistent work that made it possible to reach the conclusions in this article.

\section{REFERENCES}

[1] Suffocation deaths associated with use of infant sleep positioners--United States, 1997-2011. MMWR Morbidity and mortality weekly report. 2012 Nov 23;61(46):933-7. PubMed PMID: 23169313. Epub 2012/11/22. eng.

[2] Vandenplas Y, Benatar A, Cools F, Arana A, Hegar B, Hauser B. Efficacy and tolerability of cisapride in children. Paediatric drugs. 2001;3 (8):559-73. PubMed PMID: 11577921.

[3] Quigley EM. Cisapride: what can we learn from the rise and fall of a prokinetic? Journal of digestive diseases. 2011 Jun;12(3):147-56. PubMed PMID: 21615867. Epub 2011/05/28. eng.

[4] Tjon JA, Pe M, Soscia J, Mahant S. Efficacy and Safety of Proton Pump Inhibitors in the Management of Pediatric Gastroesophageal Reflux Disease. Pharmacotherapy. 2013 May 26. PubMed PMID: 23712734.

[5] Canani RB, Cirillo P, Roggero P, Romano C, Malamisura B, Terrin G, et al. Therapy with gastric acidity inhibitors increases the risk of acute gastroenteritis and community-acquired pneumonia in children. Pediatrics. 2006 May;117(5):e817-20. PubMed PMID: 16651 285.

[6] Nazer D, Thomas R, Tolia V. Ethnicity and gender related differences in extended intraesophageal $\mathrm{pH}$ monitoring parameters in infants: a retrospective study. BMC pediatrics. 2005;5:24. PubMed PMID: 16026617. Pubmed Central PMCID: 1188060.

[7] Gunasekaran TS, Hassall EG. Efficacy and safety of omeprazole for severe gastro esophageal reflux in children. The Journal of pediatrics. 1993 Jul;123(1):148-54. PubMed PMID: 8320610.

[8] Hassall E. Wrap session: is the Nissen slipping? Can medical treatment replace surgery for severe gastroesophageal reflux disease in children? The American journal of gastro enterology. 1995 Aug;90(8):1212-20. PubMed PMID: 7639217.

[9] van der Pol RJ, Smits MJ, van Ëijk MP, Omari TI, Tabbers MM, Benninga MA. Efficacy of proton-pump inhibitors in children with gastro esophageal reflux disease: a systematic revieë. Pediatrics. 2011 May;127(5):925-35. PubMed PMID: 21464183. 
[10] Hassall E, Kerr W, El-Serag HB. Characteristics of children receiving proton pump inhibitors continuously for up to 11 years duration. The Journal of pediatrics. 2007 Mar;150(3):262-7, 7 e1. PubMed PMID: 17307542.

[11] El Mouzan MI, Abdullah AM. The diagnosis of gastroesophageal reflux disease in children. Saudi medical journal. 2002 Feb;23(2):164-7. PubMed PMID: 11938391.

[12] Stephen TC,Younoszai MK, Massey MP, Fellows RA. Diagnosis of gastroesophageal reflux in pediatrics. The Journal of the Kentucky Medical Association. 1994 May;92(5):188-91. PubMed PMID: 8027639.

[13] Pascu O, Lencu M. Barrett's Esophagus. Romanian journal of gastroenterology. 2004 Sep;13(3):219-22. PubMed PMID: 15470535

[14] Simonka Z, Paszt A, Abraham S, Pieler J, Tajti J, Tiszlavicz L, et al. The effects of laparoscopic Nissen fundoplication on Barrett's esophagus: long-term results. Scandinavian journal of gastroenterology. 2012 Jan;47(1):1321. PubMed PMID: 22150083.

[15] Heikenen JB, Werlin SL. Esophageal biopsy does not predict clinical outcome after percutaneous endoscopic gastrostomy in children. Dysphagia. 2000 Summer;15(3):1679. PubMed PMID: 10839831.

[16] Cinquetti M, Zoppi G. [Intraesophageal pH measurement in childhood: the technic and indications]. La Pediatriamedica e chirurgica : Medical and surgical pediatrics. 1994 SepOct;16(5):433-9. PubMed PMID: 7885951. La $\mathrm{pH}$-metriaintraesofagea in eta pediatrica: tecnicaedindicazioni.

[17] Assadamongkol K, Phuapradit P, Petsrikun K, Viravithya W. Gastroesophageal reflux in children: correlation of symptoms with 24-hour esophageal $\mathrm{pH}$ monitoring. Journal of the Medical Association of Thailand = Chotmaihetthangphaet. 1993 Oct;76 Suppl 2:49-54. PubMed PMID: 7823006.

[18] Semeniuk J, Kaczmarski M. 24-hour esophageal $\mathrm{pH}$ monitoring in children with pathological acid gastroesophageal reflux: primary and secondary to food allergy.Part I. Intraesophageal $\mathrm{pH}$ values in distal channel; preliminary study and control studies--after 1, 2, 4 and 9 years of clinical observation as ëell as dietary and pharmacological treatment. Advances in medical sciences. 2007;52:199205. PubMed PMID: 18217419.

[19] Armas Ramos H, Molina Arias M, Pena Quintana L, EizaguirreSexmilo I, Juste Ruiz M, Sanchez Ruiz F, et al. [Current indications of esophageal $\mathrm{pH}$-monitoring]. Analesespanoles de pediatria. 2002 Jan;56(1):49-56. PubMed PMID: 11792245. Indicacionesactuales de la monitorizacion de la pHmetriaesofagica.

[20] Hoeffel JC, Lascombes P, Schmitt M, Galloy MA. [Peptic esophagitis and scoliosis in children]. Annales de pediatrie. 1992 Nov;39(9):561-5. PubMed PMID: 1463303. Oesophagitepeptique et scoliose chez l'enfant.

[21] Chidambaran V, Gentry C, Ajuba-Iwuji C, Sponsellar PD, Ain M, Lin E, et al. A Retrospective Identification of Gastro esophageal Reflux Disease as a Neë Risk Factor for Surgical Site Infection in Cerebral Palsy Patients After Spine Surgery. Anesthesia and analgesia. 2013 May 17. PubMed PMID: 23687234.

[22] van der Zee DC, Bax NM. Laparoscopic Thal fundoplication in severely scoliotic children. Surgical endoscopy. 1995 Nov;9(11):1197-8. PubMed PMID: 8553233.

[23] Goessler A, Huber-Zeyringer A, Hoellwarth ME. Does epilepsy influence the outcome of antireflux procedures in neurologically impaired children? Pediatric surgery international. 2006 Jun;22(6):485-90. PubMed PMID: 16736214.

[24] Goessler A, Huber-Zeyringer A, Hoellëarth ME. Recurrent gastroesophageal reflux in neurologically impaired patients after fundoplication. Actapaediatrica. 2007 Jan;96(1):87-93. PubMed PMID: 17187611.

[25] Bergmeijer JH, Bouquet J, Hazebroek FË. Normal ranges of 24-hour $\mathrm{pH}$-metry established in corrected esophageal atresia. Journal of pediatric gastroenterology and nutrition. 1999 Feb;28(2):162-3. PubMed PMID: 9932848.

Citation: Saimir Heta, Kastriot Haxhirexha, Virtut Velmishi, Nevila Alliu, Ilma Robo, Gastro-oesophageal Reflux, Some Data on Diagnosis and Clinical Evaluation. ARC Journal of Clinical Case Reports. 2019; 5(1): 20-26. doi:dx.doi.org/ 10.20431/2455-9806.0501005.

Copyright: (c) 2019 Authors. This is an open-access article distributed under the terms of the Creative Commons Attribution License, which permits unrestricted use, distribution, and reproduction in any medium, provided the original author and source are credited. 